\title{
Magnitude And Associated Factors Of Delayed Immunization Among Children Aged11 -23 Months In Edagahamus Town, Tigray, Ethiopia, 2018
}

Merhawit Gebremeskel Hagos

Aksum University

Teferi Gebru Gebremeskel ( $\nabla$ teferigebru12@gmail.com )

Aksum university https://orcid.org/0000-0002-8276-5685

Selam Shushay Kassahun

Adigrat University

Birhane Hailu Gebrezgi

Aksum University

Manay Kifle Woldegebriel

Aksum University

\section{Research article}

Keywords: Child immunization, Delay to be immunized, Vaccine-preventable diseases

Posted Date: July 12th, 2019

DOI: https://doi.org/10.21203/rs.2.11295/v1

License: (c) (1) This work is licensed under a Creative Commons Attribution 4.0 International License. Read Full License 


\section{Abstract}

Background Delay in receiving immunization is a major public health problem that has been associated with vaccine preventable disease epidemics. In Ethiopia, many children have not received the benefits of age appropriate immunization; thus more than $90 \%$ of child deaths are largely due to preventable communicable diseases. Therefore, assessment of magnitude and associated factors of delayed child immunization is essential to prevent morbidity and mortality among children. Objective To assess magnitude and factors associated with delayed immunization among 11 -23 months old children in Edagahamus Town, Tigray, Ethiopia, 2018 G.C. Method and materials A community based Cross-Sectional study was carried out on July1-30, 2018. Simple random sampling method was used to select study participants. Information was collected using structured, pre-tested questionnaire. Vaccination dates were obtained from children immunization cards and timeliness assessed based on the recommended age ranges. Data were entered and analyzed using SPSS version 20.0. Variable with P-value $<0.2$ in bivariatewere exported to multivariate. The strength of association was identified using odds ratio with $95 \%$ confidence interval $(\mathrm{Cl})$ and P-value of $<0.05$ in multivariate was taken statistically significant. Results In this study the overall magnitude of delayed immunization was29.5\%(95\% Cl 26.7-45). Private firm work of mothers(AOR=0.205 95\% $\mathrm{Cl} 0.068-0.617)$, sickness of the child(AOR=11.8, 95\% $\mathrm{Cl} 6.16-22.65)$, Mothers who attend tertiary education (AOR 0.169, 95\% $\mathrm{Cl} 0.032-0.882$ ) and secondary education (AOR $0.269,95 \% \mathrm{Cl} 0.114-0.636$ ) were significantly associated with delayed immunization. Conclusion From the study it is concluded that the magnitude of delayed immunization for children aged 12-23 months is high (29.5\%) in Edagahamus. Delayed immunizations of children were predicted by Mother's occupation, education and experience of illness of the child.

\section{Background}

Vaccine-preventable diseases cause over three million childhood deaths each year globally especially in the developing countries $(1,2)$. From the nearly 8.8 million less than five years old children die each year, greater than $20 \%$ of those deaths are due to Vaccine preventable diseases (VPD)(3). VPD is a major cause of morbidity and mortality in children under five years of age in developing countries in general and Ethiopia in particular(4). Ethiopia has experienced many VPD outbreaks as well as morbidity and mortality from VPD(5, 6). According to EDHS 2016; childhood mortality rates have declined since 2000 , however, infant and under-5 mortality rate in Ethiopia was 48/1000 and 67/1000 respectively(7). Immunization is the most important public health interferences against VPD(8). It presently averts more than 2.5 million deaths every year in all age groups from diphtheria, tetanus, pertussis (whooping cough), and measles $(9,10)$.In Ethiopia nearly 4 in 10 children age 12-23 months have received all eight basic vaccinations; one dose each of BCG and measles and three doses each of Pentavalent, PCV, Rota and polio vaccine. Immunization is a key element of the health extension program package. However, timely and full vaccination coverage has not been completed in Ethiopia as planned, thus more than $90 \%$ of child deaths are largely due to preventable communicable diseases and nutritional disorders(20). In Edagahamus, the Expanded Program on Immunization (EPI) schedule is not applied as wished; as a result, many children have not received the benefits of timely and age-appropriate immunization. So, improving timely and age-appropriate immunization delivery would require a better understanding of reasons for the delay(18). Delays in receiving immunization have been reported globally(21). In the United States of America, up to 40 percent of parents delay or refuse their 
children's vaccine (16). $63.3 \%$ of the Gambian children had a delay in the mentioned age range to receive at least one of the studied vaccines(1). In Uganda, less than half of all children received all vaccines within the recommended time(22). According to different literatures, factors that are associated with delayed immunization includes; marital status, educational status, occupation, income, service accessibility, transportation, distance, place of birth, birth order, number of children in the household, sickness of the child, Forget/don't know the due date and so on $(1,19,22,23)$. Little is known about delayed immunization and as per the investigators, no studies were conducted to assess delayed immunization. Therefore, this study aimed to assess the magnitude and factors associated with delayed immunization among $11-23$ months old children in Edagahamus.

\section{Methods}

Study setting

A community-based cross-sectional study was conducted from July 1-30/ 2018 at Edagahamus city, Tigray regional state of Ethiopia. Edagahamus is founded in the eastern zone of Tigray, wereda Saesie Tsaida Amba; which is located885 Km north of the Ethiopian capital city of Addis Ababa, $105 \mathrm{Km}$ east of the Tigray capital city Mekelle and around $20 \mathrm{Km}$ near to Adigrat. Edagahamus is divided into four kebeles and the total population was 21,993 ; from those 10,031 were male and 11,962 were female(2006/2012 census). There is only one health center in Edagahamus and the total number of under two-year children is 795 .

\section{Participants}

Sampled children aged $11-23$ months old living in Edagahamus and who fulfill the inclusion criteria were taken as the study population. Households that have one living child aged between 11-23 months old who have the vaccination card are included, While Households who have children aged between 11-23 months old who do not complete their vaccination (drop out) were excluded.

Sample size determination and Sampling technique

The sample size was calculated using a single population proportion formula was used with the following assumption: Prevalence of children who had delayed vaccination in Gambia $=63.3 \%$ (1),95\% of confidence interval(1.96), $5 \%$ margin of sampling error tolerated, $10 \%$ of non-response rate, then the final sample size are 393. A simple random sampling method was used to select study subjects using a sampling frame obtained from the health extension workers. The mothers' identity and the households' numbers that are used by the Health extension workers were used to identify the selected households. In the case of two or more children in the household, one child was selected using the lottery method. Samples were allocated to each kebeles using a proportion to the size allocation.

Study Variables

Dependent Variable

Delayed immunization 
Socio-demographic and economic factors, Maternal/caregiver factors, Child factors, and Service related factors.

\section{Definition of terms}

BCG (birth - 8 weeks), Penta1, PCV1, Rota1 and OPV1 (6 weeks - 14 weeks); Penta2, PCV2, Rota2 and OPV2 (10 weeks - 18 weeks); Penta3, PCV3 and OPV3 (14 weeks - 24 weeks)] and measles vaccine (9 months -11 months). Timeliness of vaccination of a particular antigen was assessed against the WHO recommended range as already indicated above and Children who have delayed at receiving at least one vaccine considered as delayed (1). Timely: if the vaccine was received within the recommended period above. Delayed: if received after the window period

\section{Data collection tools and techniques}

Data was collected by using an interviewer-administered and structured questionnaire adapted from WHO survey questions and related pieces of literature according to the objectives $(1,19,22,23,30)$. The questionnaire includes Socio-demographic and economic factors, Maternal/caregiver factors, Child factors, and Service related factors.

Data quality assurance and control

Four Diploma holders Midwife data collectors and two BSC holders Midwives were recruited from another area outside of the study site and they were given training for three days. The supervisors followed the process of data collection daily, checked the data completeness consistency and communicate with principal investigator daily.

Data Processing and Analysis

data was coded, cleaned, recorded and entered into Epi info 7and finally export to SPSS version 20.00 for analysis. Simple descriptive summary statistics were done. Tables, statements, charts, and graphs were used to present the result of the analyzed data. Associations between independent and dependent variables were analyzed first using bivariate logistic regression analysis. Variables that had $p<0.2$ on bivariate analysis were entered into multivariable logistic regression analysis. The statistical association between the different independent variables about dependent was measured using OR, AOR, $95 \% \mathrm{Cl}$ and P-values $<0.05$ was considered statistically significant.

\section{Results}

Socio-demographic Character of the study participants

A total of 393 mothers of children aged between 11-23 months old were interviewed from four kebeles, with a response rate of $100 \%$. Out of the total study subjects, $222(56.5 \%)$ have children aged 11-17 months, while $171(43.5 \%)$ were aged 18-24 months. The mean ( \pm SD) age of the children was $17( \pm 6)$ months old. Female 
children were 208 (52.9\%) of the total study Subjects. The age range of mothers included in the study was 17-43 years, which is a childbearing age range. The mean $( \pm S D)$ age of the mothers was $29.4( \pm 5.3)$ years old. (Table 1)

Maternity-related characteristics

About $327(83.2 \%)$ of mothers know the immunization schedule. A total of $278(70.7 \%)$ of the mothers have got health education, particularly about immunization during antenatal and postnatal care while they were pregnant and after the birth of the child. (Table 2)

Service-related characteristics

About $44(11.2 \%)$ returned home due to a lack of vaccine. About 246(62.6\%) mothers get advice during the immunization period that some vaccines had a too serious side effect. (Table 3)

The magnitude of age untimely vaccination

From the total respondents $116(29.5 \%, 95 \% \mathrm{Cl} 26.7 \%-45 \%)$. had experienced delay at least one of their immunization. For BCG 41 (10.4\%) of the respondents were presented after the age of 8 weeks and delayed for up to two months. For the first dose of Pentavalent, PCV, Rota, and polio vaccines 7 (1.7\%) of the respondents were presented after the age of 14 weeks and delayed for up to one month and a half. For the second dose of Pentavalent, PCV, Rota, and polio vaccines 13(3.3\%) of the respondents were presented after the age of 18 weeks and delayed for up to two months. For the third dose of Pentavalent, PCV and polio vaccines $26(6.6 \%)$ of the respondents were presented after the age of 24 weeks and delayed for up to two months. For measles vaccine $29(7.3 \%)$ of the children were presented after the age of 11 months and $5.2 \%$ and $1.4 \%$ were delayed for up to three and seven months respectively(figure 1 ).

Factors associated with delayed immunization

In the bivariate logistic regression maternal occupation, marital status, educational status, lack of vaccines, lack of appointment, sickness of the child and don't know the due were associated with delayed immunization at $\mathrm{p}$ - the value of less than 0.2. In multivariate logistic regression analysis sickness of the child, mothers' occupation and education have significantly associated. Accordingly, Children of mothers who were employed at private occupations were less likely to delay their vaccines (AOR $0.20595 \% \mathrm{Cl} 0.068$ 0.617) compared to children of mothers who were a housewife. Mothers who had tertiary education (AOR $0.169,95 \% \mathrm{Cl} 0.032-0.882$ ) and secondary education (AOR $0.269,95 \% \mathrm{Cl} 0.114-0.636$ ) were less likely to delay their infant's immunization compared to those mothers with no education. Sick child on the appointment day was more likely to delay (AOR $11.36,95 \% \mathrm{Cl} 4.68-27.55)$ than those healthy.

\section{Discussion}

This study aimed to assess the magnitude and factors associated with immunization delay among 11-23 months old children. In this study, the overall prevalence of delayed immunization among the study participants was found to be $29.5 \%(95 \% \mathrm{Cl} 26.7 \%-45 \%)$. It is lower as compared with the study done in 
Gambia $63.3 \%$ (1). This difference might be attributed due to the difference in educational background and degree of knowledge towards immunization. It is higher as compared with the study done in Atlanta $25.8 \%$ (24). This difference might be due to the difference in the study population. However, it is similar to the study done among Norwegian children 44.7 \% (23). This is justified due to the similarity in the study population, Vaccinations are mainly provided by public health nurses and all services are voluntary and free of charge. The occupation was significantly associated with delayed vaccination; in this study private firm work of mothers was positively associated with timeliness, which is similar to the study done among Gambian children (1). This could be due to, housewife women might be fully engaged at home with domestic tasks hence they tend to forget their children's vaccination appointments. Educational status of the mother/caretaker was a predictor for delayed child immunization; in this study maternal education beyond secondary level was positively associated with timeliness, Similar to the study done in Nigeria(21), Gambia(1) and Iran(19). This is attributed because highly educated mothers are more willing to seeking care than other mothers. The sickness of the child was also associated with delayed vaccination similar to the study done in Nigeria and Shenzhen, China(21, 30). This might be justified because it is possible to delay if a child were sick during the recommended immunization period. Socio-economic status and the number of children in the households were not predictors for delayed child immunization in this study, which is different from studies in Gambia and Uganda, which indicates income-related factors hindered utilization of immunization services so that children with several siblings were more likely to have untimely vaccinations, that higher cost and demands can easily discourage to vaccinate their children $(1,22)$. This difference could be explained by the fact that free service for immunization is implementing in Ethiopia so that higher costs and demands were not a problem among families participated in this study.

\section{Conclusions}

From the study, it is concluded that the magnitude of Delayed immunization for children aged 12-23 months is high (29.5\%) in Edagahamus. Delayed immunizations of children were predicted by the Mother's occupation, education, and experience of illness of the child. Therefore it is important to consider education as a vital for the attainment of full immunization which intern raises the need of the community and creates maternal awareness about the importance of child immunization. There is a need to disseminate information on the importance of mothers occupation that most of the mothers with domestic works have more likely to delay immunization.

\section{Abbreviations}

BCG - Bacillus Calmette-Guerin , EDHS - Ethiopia Demographic Health Survey, EPI - Expanded Program on Immunization, FMOH - Federal Ministry of Health ,MDG - Millennium development goal ,MMR - MeaslesMumps-Rubella , MoH - Ministry of Health, MU, CHS - Mekele University College of Health Science, OPV Oral Polio Vaccine, SE - Side Effect, VPD - Vaccine Preventable Diseases, PCV - Pneumonia Vaccine, SNNP - Southern Nation and Nationalities, SOS - Sustainable Outreach Services, UNICEF - United Nations International Children's Education Fund, WHO - World Health Organization

\section{Declarations}


Ethical clearance was obtained from the Ethical Review Board of the Institute of Public Health Mekele University. Permission to conduct the study was obtained from Edagahamus City administrative bodies Health department. Verbal and written consents were obtained after explaining their full right to refuse, withdraw any time, without any explaining or giving reasons. Information's obtained from individuals participants were kept secure and confidential. Names and other identifying data of respondents were made by using code throughout the study process to obtain confidentiality. Finally, data were collected according to the standard questionnaire prepared.

\section{Consent for publication}

Not applicable

\section{Availability of data and materials}

The datasets used during the current study available from the corresponding author on reasonable request.

\section{Computing interest}

The authors declare that they have no competing interests.

\section{Funding}

Mekele University was our fund agent to conduct this study. The role of Mekele University was providing appropriate training to develop the proposal, funding money to our data collectors and following how the study is going on, finally, our University provides us basic training which was helpful for our study.

\section{Authors' contributions}

MG designed the study, performed statistical analysis, and drafted the paper. TG, SS, BH, and MK participated in paper writing. All authors contribute to the data analysis and read and approved the final paper.

Acknowledgments

We are highly indebted to all participants of the study, supervisors of data collection and data collectors for their worthy efforts and participation in this study. We are also thankful for administrative bodies at all levels who endorsed us to undertake these studies.

\section{References}

1. Odutola A, Afolabi MO, Ogundare EO, Lowe-Jallow YN, Worwui A, Okabe J, et al. Risk factors for delay in age-appropriate vaccinations among Gambian children. BMC health services research. 2015;15(1):346.

2. Dayan GH, Shaw KM, Baughman AL, Orellana LC, Forlenza R, Ellis A, et al. Assessment of delay in ageappropriate vaccination using survival analysis. American journal of epidemiology. 2006;163(6):561-70. 
3. Drain PK. Vaccine Preventable Diseases and Immunization Programs. Global Health Education Consortium (GHEC): World Health Organization (WHO). 2012;2004.

4. Atnafu A, Otto $\mathrm{K}$, Herbst $\mathrm{CH}$. The role of $\mathrm{mHealth}$ intervention on maternal and child health service delivery: findings from a randomized controlled field trial in rural Ethiopia. mHealth. 2017;3(9).

5. Hailey Gebretnsae Aregawi. Determinants of defaulting from completion of child immunization in Laelay Adiabo District, Tigray Region, Northern Ethiopia: A case-control study. 2017.

6. Etana B, Deressa W. Factors associated with complete immunization coverage in children aged 12-23 months in Ambo Woreda, Central Ethiopia. BMC public health. 2012;12(1):566.

7. ETHIOPIA DEMOGRAPHIC HEALTH SURVEY. 2016.

8. Mohammed RT. Assessment of factors associated with incomplete immunization among children aged 12-23 months in Ethiopia. 2016.

9. Organization WH. Global immunization data. February 2014. 2014.

10. Legesse E, Dechasa W. An assessment of child immunization coverage and its determinants in Sinana District, Southeast Ethiopia. BMC Pediatrics. 2015;15(1):31.

11. Federal Ministry of Health AA. COMPREHENSIVE MULTI-YEAR PLAN 2016 - 2020. 2015.

12. Negussie A, Kassahun W, Assegid S, Hagan AK. Factors associated with incomplete childhood immunization in Arbegona district, southern Ethiopia: a case-control study. BMC public health. 2015;16(1):27.

13. Lakew Y, Bekele A, Biadgilign S. Factors influencing full immunization coverage among 12-23 months of age children in Ethiopia: evidence from the national demographic and health survey in 2011. BMC public health. 2015;15(1):728.

14. AWINO OJ. DETERMINANTS OF IMMUNIZATION COVERAGE AMONG CHILDREN AGED 12-23 MONTHS IN KENYA. 2016.

15. Salmon DA, Moulton LH, Omer SB, Patricia deHart M, Stokley S, Halsey NA. Factors associated with refusal of childhood vaccines among parents of school-aged children: a case-control study. Archives of pediatrics \& adolescent medicine. 2005;159(5):470-6.

16. Haelle T. Delaying vaccines increases risks-With no added benefits. Scientific American. 2014.

17. Lisa M. Calhoun AMvE. Determinants and Coverage of Vaccination in Children in Western Kenya from a 2003 Cross-Sectional Survey. 2003.

18. Lieu TA, Black SB, Ray P, Chellino M, Shinefield HR, Adler NE. Risk factors for delayed immunization among children in an HMO. American Journal of Public Health. 1994;84(10):1621-5.

19. Mohammadbeigi A, Mokhtari M, Zahraei SM, Eshrati B, Rejali M. Survival analysis for predictive factors of delay vaccination in Iranian children. International journal of preventive medicine. 2015;6.

20. Health FDRoEMo. Health Sector Development Programme IV. 2010.

21. Sadoh AE, Sadoh WE, Uduebor J, Ekpe P, Iguodala O. Factors contributing to delay in commencement of immunization in Nigerian infants. Tanzania journal of health research. 2013;15(3).

22. Babirye JN, Engebretsen IM, Makumbi F, Fadnes LT, Wamani H, Tylleskar T, et al. Timeliness of childhood vaccinations in Kampala Uganda: a community-based cross-sectional study. PloS one. 
2012;7(4):e35432.

23. Riise $\emptyset R$, Nøkleby H, Laake I, Haugen IL, Storsæter J, Bergsaker MAR. Monitoring of timely and delayed vaccinations: a nation-wide registry-based study of Norwegian children aged $<2$ years. BMC Pediatrics. 2015;15(1):180.

24. Smith PJ, Humiston SG, Marcuse EK, Zhao Z, Dorell CG, Howes C, et al. Parental delay or refusal of vaccine doses, childhood vaccination coverage at 24 months of age, and the Health Belief Model. Public health reports. 2011;126(2_suppl):135-46.

25. Smith PJ, Humiston SG, Parnell T, Vannice KS, Salmon DA. The association between the intentional delay of vaccine administration and timely childhood vaccination coverage. Public health reports. 2010;125(4):534-41.

26. Gilkey MB, McRee A-L, Magnus BE, Reiter PL, Dempsey AF, Brewer NT. Vaccination confidence and parental refusal/delay of early childhood vaccines. PloS one. 2016;11(7):e0159087.

27. Bobo JK, Gale JL, Thapa PB, Wassilak SG. Risk factors for delayed immunization in a random sample of 1163 children from Oregon and Washington. Pediatrics. 1993;91(2):308-14.

28. Hu Y, Li Q, Luo S, Lou L, Qi X, Xie S. Timeliness vaccination of measles-containing vaccine and barriers to vaccination among migrant children in East China. PloS one. 2013;8(8):e73264.

29. Ujwala U. Ukey a DPD, Dr. Dhruv S. Chitrec, Dr. Srinivas Pusulurid. Factors Related To Delayed Immunisation Among Children Below 5 Years. International Journal of Biological \& Medical Research. 2011;2 (4):1171 - 2.

30. Lin W, Xiong Y, Tang H, Chen B, Ni J. Factors associated with delayed measles vaccination among children in Shenzhen, China: A case-control study. Human vaccines \& immunotherapeutics. 2014;10(12):3601-6.

\section{Tables}

Table 1: Socio-demographic characteristics of the respondents in Edagahamus, Tigray, Ethiopia, 2018 (n=393). 


\begin{tabular}{|c|c|c|c|c|}
\hline Variable & Category & Frequency & Percent (\%) & Remark \\
\hline \multirow[t]{2}{*}{ Sex of child } & Female & 208 & 52.9 & \\
\hline & Male & 185 & 47.1 & \\
\hline \multirow[t]{2}{*}{ Age of child } & 11-17 months & 222 & 56.5 & \\
\hline & 18-24 months & 171 & 43.5 & \\
\hline \multirow[t]{2}{*}{ Age of mother } & $\leq 30$ yrs & 244 & 62.1 & \\
\hline & $\geq 31$ yrs. & 149 & 37.9 & \\
\hline \multirow[t]{2}{*}{ Religion } & Christian & 328 & 83.5 & \\
\hline & Other & 65 & 16.5 & \\
\hline \multirow[t]{3}{*}{ Marital status } & Married/active & 302 & 76.8 & \\
\hline & never married & 39 & 9.9 & \\
\hline & Separated/widowed and divorced & 52 & 13.2 & \\
\hline \multirow[t]{2}{*}{ Ethnicity } & Tigray & 372 & 94.7 & \\
\hline & Other & 21 & 5.4 & \\
\hline \multirow[t]{4}{*}{ Educational level } & no education & 57 & 14.5 & \\
\hline & Primary & 106 & 27.0 & \\
\hline & Secondary & 191 & 48.6 & \\
\hline & University/college & 39 & 9.9 & \\
\hline \multirow[t]{5}{*}{ Occupation } & Governmental & 22 & 5.6 & \\
\hline & Private & 59 & 15.0 & \\
\hline & Daily & 40 & 10.2 & \\
\hline & Student & 16 & 4.1 & \\
\hline & Housewife & 256 & 65.1 & \\
\hline \multirow[t]{4}{*}{ Average monthly income } & $<500$ birr & 42 & 10.7 & \\
\hline & $500-1000$ & 119 & 30.3 & \\
\hline & $>1000$ & 192 & 48.3 & \\
\hline & Unknown & 42 & 10.7 & \\
\hline \multirow[t]{3}{*}{ Birth order of the child } & $1^{\text {st }}$ born & 55 & 14.0 & \\
\hline & $2^{\text {nd }}$ born & 161 & 41.0 & \\
\hline & $>3^{\text {rd }}$ born & 177 & 45.0 & \\
\hline
\end{tabular}

ble 2: Distribution of maternity-related characteristics of Edagahamus, Tigray, Ethiopia, 2018 (n=393) 


\begin{tabular}{|c|c|c|c|}
\hline Variable & Category & Frequency & $\begin{array}{l}\text { Percent } \\
(\%)\end{array}$ \\
\hline \multirow{2}{*}{$\begin{array}{l}\text { Health education about vaccination and related topics during } \\
\text { PNC/ANC }\end{array}$} & Yes & 278 & 70.7 \\
\hline & No & 115 & 29.3 \\
\hline \multirow[t]{2}{*}{ Place of birth } & Own home & 47 & 12.0 \\
\hline & $\begin{array}{l}\text { Health } \\
\text { facility }\end{array}$ & 346 & 88.0 \\
\hline \multirow[t]{2}{*}{ Illness of child on the appointment period } & Yes & 42 & 10.7 \\
\hline & No & 351 & 89.3 \\
\hline \multirow[t]{2}{*}{ Don't know it was due/forget } & Yes & 28 & 7.1 \\
\hline & No & 365 & 92.9 \\
\hline \multirow[t]{2}{*}{ Fear of side effect } & Yes & 27 & 6.9 \\
\hline & No & 366 & 93.1 \\
\hline \multirow[t]{2}{*}{ Do you think it is important to get a vaccine? } & Yes & 381 & 96.9 \\
\hline & No & 12 & 3.1 \\
\hline \multirow[t]{2}{*}{ Do you know immunization commences at birth? } & Yes & 311 & 79.1 \\
\hline & No & 82 & 20.9 \\
\hline \multirow[t]{2}{*}{ Do you know the immunization schedule? } & Yes & 327 & 83.2 \\
\hline & No & 66 & 16.8 \\
\hline \multirow[t]{2}{*}{ Do you think immunity could be achieved with vaccination? } & Yes & 362 & 92.1 \\
\hline & No & 31 & 7.9 \\
\hline \multirow[t]{2}{*}{ Do you think VPD could be serious? } & Yes & 342 & 87.0 \\
\hline & No & 51 & 13.0 \\
\hline
\end{tabular}

Jle 3: Distribution of service-related characteristics of Edagahamus, Tigray, Ethiopia, 2018 (n=393).

\begin{tabular}{llrr} 
Variable & Category & $\begin{array}{c}\text { Frequency } \\
\text { The child might develop side effect from the shot }\end{array}$ & $\begin{array}{c}\text { Percent } \\
\text { (\%) }\end{array}$ \\
& $\begin{array}{l}\text { Great } \\
\text { deal }\end{array}$ & 314 & 79.9 \\
\cline { 2 - 4 } & A little & 61 & 15.5 \\
\cline { 2 - 4 } & Not at all & 18 & 4.6 \\
\hline $\begin{array}{l}\text { Advised you some vaccines had too serious SE during immunization } \\
\text { period }\end{array}$ & Yes & 246 & 37.4 \\
\hline Satisfaction with the practice of providers & No & 147 & 63.9 \\
\hline Lack of vaccine & Yes & 251 & 36.1 \\
\cline { 2 - 4 } & No & 142 & 11.2 \\
\hline Lack of appointment & Yes & 349 & 88.8 \\
\cline { 2 - 4 } & No & 20 & 5.1 \\
\hline
\end{tabular}

Table 4: Factors associated with delayed immunization among 11-23 months old children in Edagahamus Town, Tigray, Ethiopia, and 2018G.C 


\begin{tabular}{|c|c|c|c|c|c|c|}
\hline Variable & $\begin{array}{c}\text { Delay } \\
\text { n (\%) }\end{array}$ & $\begin{array}{l}\text { Timely } \\
\text { n (\%) }\end{array}$ & COR & $\mathbf{P}$ & AOR & $\mathbf{P}$ \\
\hline \multicolumn{7}{|l|}{ Occupation } \\
\hline Governmental & $2(9.1)$ & $20(90.9)$ & $0.184(0.042 ; 0.807)$ & 0.025 & $0.663(0.10-4.384)$ & 0.669 \\
\hline Private & $10(16.9)$ & $49(83.1)$ & $0.376(0.182 ; 0.779)$ & 0.008 & $0.205(0.068-0.617)$ & 0.005 \\
\hline Daily laborer & $28(70)$ & $12(30)$ & $4.304(2.088 ; 8.871)$ & 0.000 & $1.881(0.602-5.874)$ & 0.277 \\
\hline Student & $9(56.3)$ & $7(43.8)$ & $2.37(0.855 ; 6.58)$ & 0.097 & $3.462(0.707-16.95)$ & 0.125 \\
\hline Housewife & $90(35.2)$ & $166(64.8)$ & 1 & 1 & 1 & 1 \\
\hline \multicolumn{7}{|l|}{ Education } \\
\hline Tertiary & $4(10.3)$ & $35(89.7)$ & $0.072(0.022 ; 0.23)$ & 0.000 & $0.169(0.032-0.882)$ & 0.035 \\
\hline Secondary & $52(27.2)$ & $139(72.8)$ & $0.235(0.126 ; 0.438)$ & 0.000 & $0.269(0.114-0.636)$ & 0.003 \\
\hline Primary & $48(45.3)$ & $58(54.7)$ & $0.520(0.270 ; 1.003)$ & 0.051 & $0.828(0.340-2.019)$ & 0.678 \\
\hline Uneducated & $35(61.4)$ & $22(38.6)$ & 1 & 1 & 1 & 1 \\
\hline \multicolumn{7}{|l|}{ Marital status } \\
\hline Married & $90(29.8)$ & $212(70.2)$ & $0.337(0.185 ; 0.614)$ & 0.000 & & \\
\hline Unmarried & $20(51.3)$ & $19(48.7)$ & $0.835(0.363 ; 1.920)$ & 0.671 & & \\
\hline Separated & $29(55.8)$ & $23(44.2)$ & 1 & 1 & & \\
\hline Yes & $110(32.2)$ & $232(67.8)$ & 1 & & & \\
\hline \multicolumn{7}{|l|}{ Lack of vaccine } \\
\hline Yes & $30(68.2)$ & $14(31.8)$ & $4.718(2.406 ; 9.253)$ & 0.000 & & \\
\hline No & $109(31.2)$ & $240(68.8)$ & 1 & & & \\
\hline \multicolumn{7}{|l|}{ Sickness of child } \\
\hline Yes & $30(71.4)$ & $12(28.6)$ & $5.550(2.738 ; 11.25)$ & 0.000 & $11.36(4.68-27.55)$ & 0.000 \\
\hline No & $109(31.1)$ & $242(68.9)$ & 1 & & & \\
\hline \multicolumn{7}{|c|}{ Lack of appointment } \\
\hline Yes & $12(60)$ & $8(40)$ & $2.906(1.158 ; 7.290)$ & 0.023 & & \\
\hline No & $127(34)$ & $246(66)$ & 1 & & & \\
\hline \multicolumn{7}{|l|}{ Forget } \\
\hline Yes & $17(60.7)$ & $11(39.3)$ & $3.078(1.398 ; 6.776)$ & 0.005 & & \\
\hline No & $122(33.4)$ & $243(66.6)$ & 1 & & & \\
\hline
\end{tabular}

\section{Figures}




\section{Timely versus Delayed immunization}

घ delay timely

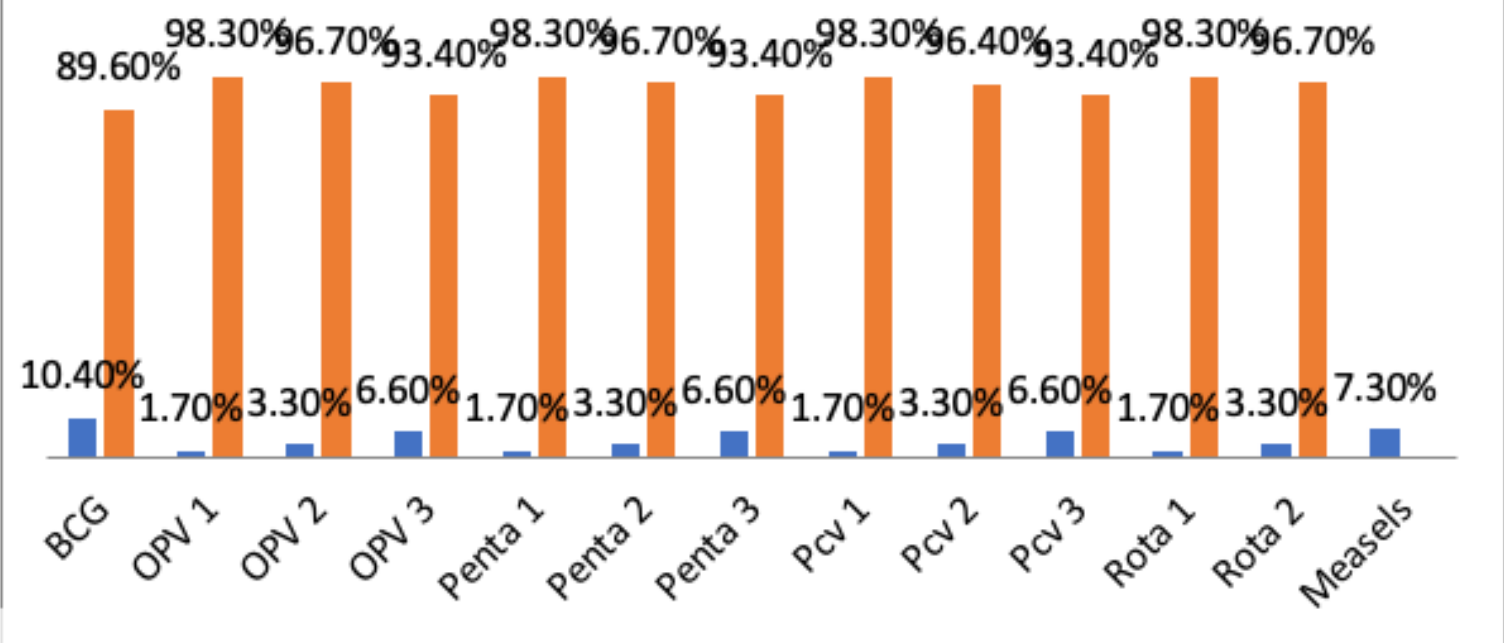

Figure 1

Timely versus delayed immunization among 11-23 months old children in Edagahamus, Tiray, Ethiopia, 2018. 